\title{
HISTÓRIAS E MEMÓRIAS DAS LUTAS POPULARES PELA ESCOLA PÚBLICA NO JARDIM UNIÃO DA VITÓRIA - LONDRINA-PR (1990-2009)
}

\author{
Maria José Ferreira Ruiz ${ }^{1}$
}

\section{RESUMO}

O texto apresenta um estudo sobre o processo histórico das lutas populares pela escola pública, empreendidas pelos trabalhadores moradores do jardim União da Vitória, bairro periférico da cidade de Londrina-PR, entre os anos de 1990 a 2009. Parte da premissa de que as lutas populares na área da educação foram e são importantes para a democratização do ensino público e gratuito. Faz uma análise conjuntural que parte do contexto econômico, político e social do referido município. Utiliza como procedimentos a pesquisa bibliográfica, a análise em documentos e reportagens em dois jornais locais e a entrevista semiestruturada. Conclui que a ampliação do sistema público de ensino, na região pesquisada, foi produto de uma luta árdua, lenta e cotidiana dos trabalhadores moradores do bairro, que conseguiram se organizar, diante das condições desiguais a que estavam e continuam submetidos. Essas lutas se traduziram na conquista das escolas, no acréscimo das vagas nos níveis e modalidades da educação e, ainda, na conquista das condições mínimas para permanecer na escola conquistada.

Palavras-chave: Lutas populares; Escola Pública; Democratização.

\section{STORIES AND MEMORIES OF POPULAR STRUGGLES FOR PUBLIC SCHOOL IN “JARDIM UNIÃO DA VITÓRIA” - LONDRINA-PR (1990-2009)}

\begin{abstract}
The paper presents a study of the historical process of popular struggles for public school, undertaken by employees and residents of "Jardim União da Vitória", suburb of the city of Londrina-PR, between the years 1990 to 2009. The popular struggles in education were and are important for the democratization of free public education. Makes a conjunctural analysis of the economic, political and social context of the city. Uses as methods the literature search, analysis of documents and news in two local newspapers and the semistructured interview. We conclude that the expansion of the public school system in the area surveyed was the product of an arduous, slow and daily struggle, of the resident workers of the neighborhood, who managed to organize in the face of unequal conditions to which they were and still are subjected. These struggles have resulted in the conquest of the schools, the increase of the vacancies in the levels and types of education and also the achievement of the minimum conditions to stay in the earned school.
\end{abstract}

Keywords: Popular Struggles; Public School; Democratization.

\section{Introdução}

Os trabalhadores pobres que residem em bairros periféricos das cidades se identificam pela condição geográfica, por residirem na mesma localidade. Portanto, eles reagem coletivamente contra a distribuição desigual dos recursos e serviços públicos - rede de esgoto, coleta de lixo, abastecimento de água, transporte, energia elétrica, educação, dentre outros. Não se identificam, porém, pelos segmentos no mundo do trabalho, o que 
qualifica as lutas mais gerais da classe trabalhadora na sociedade capitalista. Os trabalhadores desses bairros dependem dos bens e serviços públicos (dentre os quais a escola) para ter uma melhor condição de vida. Portanto, são diretamente afetados "pela ação e pela omissão do Estado no oferecimento (ou negação) daqueles serviços que são, por lei, de sua atribuição e de direito da totalidade dos habitantes da cidade". (CUNHA, 1995, p. 61).

As lutas populares na área da educação foram e são importantes para a democratização do ensino público e gratuito, principalmente, em relação ao ensino fundamental. Partindo dessa premissa, temos o objetivo neste texto de apresentar o processo de luta dos trabalhadores pela escola pública, realizada pelos moradores de um bairro pobre e periférico da zona sul do município de Londrina, norte do Paraná: o Jardim União da Vitória. A pesquisa restringe-se aos anos de 1990 a 2009, período no qual as escolas do bairro foram sendo conquistadas. O critério para a escolha do bairro a ser estudado considerou uma história de luta reconhecida e consolidada no município de Londrina e a atuação da autora de mais de vinte anos como trabalhadora da educação na localidade. Apesar de a pesquisa focar o Jardim União da Vitória, verificamos que participaram moradores de bairros circunvizinhos a ele - Jardim Cristal, Campos Elíseos e Franciscato -, o que justifica a menção que faremos a outros bairros no transcurso do texto.

O bairro selecionado possui duas escolas: a Escola Municipal Tereza Canhada Bertan e o Colégio Estadual Thiago Terra; também, o Centro de Atendimento Integral à Criança (CAIC) Dolly Jess Torresin, onde se localiza, atualmente, a Escola Municipal Zumbi dos Palmares. A Escola Estadual Rina Francovig fica nas imediações do Jardim União da Vitória e também atende a esse bairro.

Nesse bairro selecionamos, também, cinco organizações populares, a fim de localizar as lideranças comunitárias e identificar as lutas que os trabalhadores moradores encaminharam na área da educação. É importante ressaltar que nem todas as pessoas que estão atualmente na presidência dessas organizações estiveram à frente das mobilizações em prol da conquista das escolas do bairro. No entanto, o contato com essas pessoas e organizações foi importante para encontrar o fio da meada, ou seja, encontrar dados, fatos e pessoas, enfim fontes para a pesquisa. As organizações selecionadas foram: o Conselho de Cultura da Região Sul de Londrina (CONCRESUL), o Instituto de Educação Igapó, a Associação de Moradores do Jardim União da Vitória e a Associação de Mulheres União Faz a Força. A Associação de Mulheres Batalhadoras do Jardim Franciscato também nos serviu de referência. Trata-se de uma organização que está localizada no Jardim Franciscato, bairro adjacente ao Jardim União da Vitória.

É importante sinalizar que as instituições citadas não foram nossos objetos de estudo. Não nos interessamos em analisar suas naturezas e composição e nem em verificar se ocorrem processos democráticos nelas. Portanto, elas aparecem de forma secundária no estudo e nos serviram apenas para verificar a incidência do fenômeno estudado: a luta popular pela educação.

Para analisar este fenômeno, utilizamos a pesquisa bibliográfica e a pesquisa documental nas entidades analisadas e nas escolas. Ainda, fizemos as entrevistas semiestruturadas. Identificamos os projetos político-pedagógicos (PPP) das escolas selecionadas; as atas dos conselhos escolares e da Associação de Pais e Mestres- APMF das escolas ${ }^{2}$; os estatutos das organizações populares de bairro; e ainda as reportagens dos dois jornais locais da cidade de Londrina-PR: Folha de Londrina e Jornal de Londrina.

As reportagens nos jornais da cidade foram selecionadas a partir do seguinte critério: que expusessem alguma forma de protesto e mobilizações de moradores do Jardim União da Vitória por melhorias no bairro, com foco nas questões sobre as escolas públicas, 
a partir de 1990, década na qual a primeira escola pública no bairro foi construída. Realizamos, ao todo, oito visitas aos jornais da cidade entre os meses de junho e julho de 2012. Quatro visitas em cada um dos jornais.

A busca às reportagens se deu após termos acesso ao estudo de Camponez (2005), que discute a politização do espaço urbano, tendo como referência o Jardim União da Vitória, e utiliza as reportagens dos jornais como fonte de pesquisa. Nessa pesquisa, encontramos a citação de reportagens que tratavam das demandas por serviços urbanos, dentre eles a escola, até o ano 2000. Fomos aos jornais e tivemos acesso às reportagens e, além delas, ampliamos a busca até o ano de 2009. Na ocasião, já havíamos realizado as entrevistas, mas ainda nos faltavam mais dados para que pudéssemos identificar com mais elementos e detalhes o fenômeno estudado. Embora as entrevistas já apontassem para as lutas dos trabalhadores moradores do referido bairro, foi o acesso às reportagens e a análise delas que nos permitiram delinear melhor as questões referentes à pesquisa.

Os jornais são catalogados em grandes livros, sendo um livro para cada mês do ano. $\mathrm{Na}$ Folha de Londrina, além da consulta aos livros, cujas reportagens puderam ser fotocopiadas, foi possível ainda acessar aquelas de anos mais recentes, pela busca virtual (computador).

No Jornal de Londrina, tivemos fácil acesso ao acervo. No entanto, o Jornal não contava com pessoas disponíveis para auxiliar na catalogação das reportagens; assim, não obtivemos auxílio na busca dos documentos. Também não possuía a busca pelo sistema virtual, o que dificultou um pouco mais o processo. Não houve também a possibilidade de fotocopiar as reportagens. Utilizamos então a câmera fotográfica para registrá-las.

Para entender melhor a dinâmica da luta dos trabalhadores moradores do Jardim União da Vitória, realizamos sete entrevistas semiestruturadas. Cinco entrevistas com representantes das entidades selecionadas e duas com uma diretora e um ex-diretor de duas escolas do bairro. No texto, nos referimos aos entrevistados representantes das entidades, utilizando os seus primeiros nomes. O ex-diretor e a diretora são identificados pelo cargo e pelo nome da escola que representam.

A escolha dos moradores do bairro a serem entrevistados se deu a partir dos seguintes critérios: ser líder comunitário e atuar como representante nas organizações populares do Jardim União da Vitória e imediações e ter participado ou participar como membro nos colegiados de uma das escolas do bairro.

O critério utilizado para selecionar os diretores a serem entrevistados foi o maior tempo de trabalho nas escolas do Jardim União da Vitória. Julgamos que o tempo de experiência empírica nessas escolas seria importante, pois traria subsídios históricos sobre o bairro e sobre sua organização política na luta pelo acesso aos serviços públicos. Entrevistamos o ex-diretor da escola CAIC Dolly Jess Torresin, que trabalhou na Instituição por dezesseis anos, e a diretora da Escola Zumbi dos Palmares, com cinco anos de trabalho. O ex-diretor ocupou essa função 2009, quando se ausentou para concorrer ao cargo de vereador municipal em Londrina-PR, pelo Partido Social Democrático Brasileiro (PSDB). Foi eleito como suplente e ocupou uma cadeira na Câmara, devido ao afastamento de uma vereadora da casa.

Neste texto fizemos o esforço de resgatar os fatos históricos do bairro em questão a partir do ponto de vista dos trabalhadores. Sobre isso, concordamos com Zinn (2005), que aponta que os relatos do passado são quase sempre contados como são os da família. Omitem-se os conflitos de interesses e os antagonismos. Dessa forma, é tarefa do pesquisador olhar para a história de outros pontos de vista, dentro dos limites que se impõem a uma só pessoa, por muito que ela se esforce. Não tratamos de inventar vitórias aos trabalhadores ou histórias sobre as lutas pela educação, mas, sim, de recapitular e 
acrescentar fatos em relação à organização dos trabalhadores, que evidenciam que eles lutaram de diferentes formas para democratizar a escola pública e gratuita.

\section{O contexto social e político das lutas pela escola}

A luta pela abertura política e pela queda do regime militar no Brasil, na década de 1980, trouxe a efervescência dos movimentos populares em várias áreas. Na educação, destacaram-se o movimento estudantil e o movimento docente. No entanto, houve também várias manifestações em bairros periféricos das grandes cidades em prol de melhorias nas condições de vida da sua gente (GOHN, 1994).

Algumas pesquisas foram realizadas, a fim de discutir e apresentar o fenômeno da organização popular dos bairros na luta pela democratização ${ }^{3}$ da escola pública. Dentre elas destacamos os estudos de Campos (1982), Spósito (1984 e 1993), Campos (1989), Avancine (1990) e de Ghanem (1992). Consideramos que investigar esse fenômeno é uma forma de trazer para o palco da história e das pesquisas acadêmicas os sujeitos que são deixados à margem dela.

Em uma dessas pesquisas, Spósito (1984) analisou a luta popular na expansão do ensino público na cidade de São Paulo. A pesquisadora identificou que, embora o povo tenha ficado à margem da história oficial, as escolas públicas nos bairros periféricos da cidade de São Paulo foram chegando após muita luta dos moradores. Essa questão foi negligenciada, pois muitas dessas escolas quando chegaram aos bairros foram inauguradas com pompa e circunstância, como se fossem dádivas daquele governo benevolente que ocupou a gestão naquele momento.

Nas palavras de Spósito (1984),

É inegável que, em um determinado momento das transformações sociais observadas em São Paulo, a busca de melhores oportunidades educacionais integrou grande parte das aspirações das camadas populares radicadas na periferia da cidade. [...] o acesso ao curso ginasial aos poucos foi integrando o conteúdo de interesses definidos pelas classes populares, habilmente apreendidos pelas lideranças políticas do período, que levaram para esses setores as possibilidades de sua realização. (SPÓSITO, 1984, p. 21, grifos da autora).

Esse fenômeno ocorreu em cidades mais velhas, como no caso de São Paulo, e continuou a ocorrer em cidades mais novas, a exemplo da cidade de Londrina, que, atualmente, tem 78 anos.

Para contextualizar a luta popular pela escola no bairro selecionado, achamos relevante, a priori, identificar alguns fatores que levam à migração do campo para a cidade e que contribuem para a produção social dos bairros periféricos nos centros urbanos. Nesses centros, há a condensação de forças que conduzem à constituição de organizações populares que passam a reivindicar melhores condições de vida; fatores diretamente relacionados com questões econômicas engendradas pelo modo de produção atual.

Diante disso, trataremos, a seguir, da produção do espaço urbano e dos fatores que contribuíram para a formação das organizações populares em alguns bairros carentes.

Luta popular, produção do espaço urbano e formação das organizações populares

As novas formas de organização do trabalho no sistema capitalista e a mobilidade social que elas acarretam levam as populações do campo a migrar para os centros urbanos. A vida urbana é necessária para a produção e reprodução do capitalismo, tendo em vista a 
sua necessidade de produzir, de dar vazão à produção de seus produtos e serviços e à sua necessidade de criar e estimular o desejo de consumo. Esses fatores encontram no setor urbano maior possibilidade de efetivação. Nas palavras de Castells (1980, p. 20-21),

A concentração e centralização do capital, na fase monopolista do sistema, conduz à concentração econômica, social e espacial dos meios de produção e das unidades de gestão, assim como da força de trabalho necessária a seu funcionamento. A concentração espacial dos trabalhadores em cidades e áreas metropolitanas de dimensão cada vez maior determina, por sua vez, a concentração e a interdependência crescente do conjunto de meios e consumos que lhes são necessários.

A situação de vida precária leva à mobilização dos moradores de bairros que, em algumas localidades, organizam movimentos reivindicatórios para cobrar do poder público as benfeitorias necessárias para a vida, indo da instalação da rede de esgoto à construção das escolas. Nunes e Jacobi (1982), referenciando a questão do movimento citadino na Espanha, citam que ele

Apresenta uma grande diversidade, embora se unifique em torno dos seus objetivos gerais. Se desenvolve a partir de critérios bastante amplos, como associação aberta a todos os vizinhos, a defesa dos interesses reivindicatórios de todos os moradores do bairro e a vinculação aos processos mais gerais de luta pela democracia. [...] $\mathrm{O}$ desenvolvimento dos movimentos reivindicatórios de bairro e da vida associativa [...] criam uma [...] organização social que permite acumular as demandas e resultados, estabelecendo novos interlocutores da Administração. Constituem-se [em espaços] com capacidade de representação e convocatória de massas. (NUNES; JACOBI, 1982, p. 167).

Reiteramos, ainda, o dito pelo autor de que esses movimentos são organizados com critérios bastante amplos, mas, sem medo de fazer a afirmação, podemos alegar que grande parte destes movimentos é formada pela classe trabalhadora - empregada e/ou desemprega.

No texto, usamos a terminologia organizações populares de bairro para nos referir a esses movimentos. Conceituamos esse termo como mobilizações que ocorrem na zona urbana e que se caracterizam pela organização da classe trabalhadora em torno das questões de educação, saúde, moradia, transporte e outras referentes à vida coletiva.

Vimos até aqui, de forma genérica, como o espaço urbano é permeado por contradições que fomentam a luta popular. Na sequência, faremos uma sucinta apresentação de dados sobre a cidade de Londrina, que fornecerá elementos importantes para compreender melhor as lutas populares pela educação em um bairro da zona sul deste município.

\section{Londrina: progresso econômico e segregação social}

A cidade de Londrina foi fundada em 1929, elevando-se à categoria de município em 1934. Tem hoje setenta e oito anos, o que a faz uma cidade relativamente jovem, tendo em vista o grande desenvolvimento econômico alcançado. Esse crescimento econômico, no entanto, ocorreu concomitantemente à pauperização de uma boa parte da população.

O município alcançou um crescimento populacional muito acelerado. É o segundo município mais populoso do Paraná - 506.701 habitantes - e o quarto mais populoso da região Sul do Brasil. (INSTITUTO BRASILEIRO DE GEOGRAFIA E ESTATÍSTICA, 
2010). Londrina é um pólo de desenvolvimento regional e nacional e exerce grande influência sobre o norte Paraná, destacando-se como uma das cidades mais importantes da região sul do país.

A cidade foi planejada para comportar vinte mil habitantes. O número de habitantes foi superado rapidamente nos primeiros vinte anos da cidade. $\mathrm{O}$ crescimento inesperado ocorreu devido à intensa produção agrícola, tendo a economia cafeeira como sua principal atividade. A produção de café acabou por contribuir para que grandes somas de capital se deslocassem para a região de Londrina. (SILVA; MELCHIOR, 2002). O café continuou como o principal produto da cidade, que ficou conhecida como capital mundial do café, até a década de setenta.

No entanto, a cafeicultura foi prejudicada principalmente pela grande geada de 1974. Após essa década, a economia da cidade voltou-se mais para as atividades urbanas e industriais, em prejuízo da economia agrário-exportadora, assim como grande parte das cidades brasileiras. Houve uma ampliação da demanda de trabalho no comércio e na indústria de Londrina. (SILVA; MELCHIOR, 2002).

Ocorreu, então, uma acelerada mobilidade da população do campo para a região urbana. Em 1970, a cidade tinha 288.532 habitantes dos quais $43 \%$ viviam no campo. Atualmente, a cidade tem 506.645 habitantes e apenas 2,6\% (13.188 habitantes) encontram-se no campo. (INSTITUTO BRASILEIRO DE GEOGRAFIA E ESTATÍSTICA, 2010).

Dessa forma, Londrina teve seu espaço urbano estruturado da mesma forma que as maiorias das cidades que cresceram muito rapidamente, ou seja, o espaço foi ocupado de forma desordenada. Em poucas décadas, houve uma intensa migração das pessoas que habitavam no campo para a zona urbana da cidade. Londrina recebeu, também, em poucas décadas, um grande contingente de imigrantes vindos de outros Estados, principalmente de São Paulo e Minas Gerais. No espaço urbano da cidade, há todas as contradições referentes àquelas da sociedade capitalista.

As pessoas recém-chegadas do campo, muitas vezes, não conseguiram pagar pelas moradias e não tiveram ajuda espontânea do poder público. A pauperização dessas pessoas fez com que se organizassem para lutarem pelos seus direitos. Muitas delas procuraram por áreas da cidade a fim de ali se instalarem com suas famílias. Isso resultou na ocupação de algumas áreas públicas ou ainda terrenos privados em localizações distanciadas da área central. Essas regiões, por vezes, tinham características naturalmente inadequadas para habitação. Localizavam-se em encostas ou fundo de vales. Nelas, os moradores constituíram suas residências de forma precária, o que deu origem aos assentamentos bairros não regularizados pelo poder público - e favelas. (SILVA; MELCHIOR, 2002). Essa foi a história de formação do Jardim União da Vitória, bairro que selecionamos para coleta de dados empíricos. É sobre a formação desse bairro que trataremos na sequência.

\section{Jardim União da Vitória, luta e conquista do espaço urbano}

O jardim União da Vitória, como já apontado, está localizado na região sul do município de Londrina, norte do Paraná. Segundo Camponez ${ }^{4}$ (2005), o União da Vitória começou a se formar no ano de 1985 a partir da ocupação efetivada por algumas famílias em um terreno da Companhia de Habitação $(\mathrm{COHAB})$ de Londrina. O terreno pertencia à COHAB desde 1977. Estas famílias haviam migrado da zona rural do município em busca de trabalho e melhores condições de vida. A princípio, instalaram-se em favelas já constituídas na cidade - Favela Nossa Senhora da Paz, Favela Marisa e a Favela do Franciscato. 
Em agosto de 1985, quinze famílias dessas favelas se deslocaram para ocupar o terreno da $\mathrm{COHAB}$, que, imediatamente, entrou com um processo judicial de reintegração de posse. Ainda no mês de agosto foi concedida a liminar, dando ganho de causa à Companhia. As famílias, no entanto, se recusaram a sair do terreno.

A partir desse episódio, o conflito noticiado pela imprensa começou a repercutir na cidade e as famílias começaram a ganhar o apoio de alguns segmentos da cidade. $\mathrm{O}$ movimento estudantil universitário, a pastoral operária, a pastoral da terra, a Federação de Assentamentos e Favelas de Londrina e outras entidades uniram-se à causa em defesa da moradia das famílias. Diante da pressão popular, a discussão chegou aos poderes legislativo e executivo, quando Wilson Moreira (1983-1988), na época vinculado ao PMDB, foi prefeito de Londrina. A partir daí, desenrolou-se um processo conflituoso, até que, ainda no mesmo mês, o despejo foi concedido, o que ocorreu com grande truculência da polícia.

As famílias, conforme ilustra Camponez (2005), não retornaram para as favelas de origem e foram acampar em um terreno próximo à Prefeitura Municipal. José Richa (PMDB), naquela ocasião governador do Estado, foi a Apucarana - cidade próxima a Londrina. Ao saber que o governador estaria nas cidades da imediação, o grupo de famílias conseguiu formar uma comissão e angariar recursos para que ir até aquela cidade. Lá chegando, a comissão conseguiu abordar o governador para que tomasse conhecimento do fato.

O prefeito da cidade, Wilson Moreira, que também estava no evento de Apucarana, foi orientado pelo governador José Richa (PMDB) a solucionar o problema das famílias, diante da proporção que o entrevero vinha tomando na imprensa ${ }^{5}$ e da dimensão da repercussão social. O prefeito foi incumbido de dar encaminhamentos à situação das moradias das famílias, até que o Instituto Nacional de Colonização e Reforma Agrária (INCRA) tivesse condições de fazê-lo.

A prefeitura negociou com o grupo no mês de outubro de 1985 e cada uma das famílias recebeu um lote de terra, que foi liberado para o plantio, porém fez parte do acordo que a terra deveria ser destinada apenas à agricultura e não à moradia. Somente uma família, escolhida consensualmente pelo grupo, ficou morando no terreno para cuidar das sementes e dos instrumentos de trabalho. Cinco famílias voltaram para os barracos das favelas de origem e nove ficaram acampadas na margem da rodovia, próximo ao terreno da COHAB, para ficar mais fácil o acesso ao trabalho na terra.

Em 1987, outras famílias de trabalhadores do campo ocuparam o terreno, mas, sob a ameaça de despejo, saíram do local.

Em 1988, ocorreu um despejo de famílias de trabalhadores rurais que haviam ocupado uma fazenda da região. Algumas destas famílias foram para outro assentamento rural, do Movimento dos Trabalhadores Rurais Sem Terra (MST), que, na época, estava localizado próximo àquela região.

Neste ínterim, outras famílias se instalaram no assentamento urbano que estava no terreno da $\mathrm{COHAB}$, no qual algumas famílias já estavam assentadas em quinze casas que foram construídas por meio de um financiamento destinado à construção de moradias populares.

Em 1989, Antonio Belinati (na ocasião, do PDT) assumiu a prefeitura e fez promessas de legalizar a situação do terreno das famílias assentadas. Em 1990, o prefeito entregou mil e oitocentos "títulos de propriedades para moradores de quatorze bairros de Londrina, entre eles o União da Vitória [...] mas eram títulos falsos" (CAMPONEZ, 2005, p. 50). Em 1992, os moradores do Jardim União da Vitória conseguiram uma reunião com o diretor do Departamento de Urbanismo da Prefeitura e com o chefe do Departamento 
Social da COHAB para pleitear a legalização dos terrenos, nos quais os seus barracos estavam construídos. No entanto, foi apenas em 1996 que a COHAB começou o processo de cadastramento das 1.577 famílias que já moravam no terreno, naquela ocasião, quando estava na prefeitura Luiz Eduardo Cheida (PMDB -1993-1996).

Com a regularização do bairro, as ruas passaram a ter nomes. Comumente são os vereadores que escolhem os nomes das ruas das cidades, a fim de homenagear famílias tradicionais do município. No entanto, os moradores do Jardim União da Vitória, naquele período já organizados em Conselhos e Entidades, conseguiram indicara nominação das ruas. Assim, puderam fazer homenagens a moradores já falecidos, a trabalhadores próximos a eles, a entidades e organizações que apoiaram o movimento pela conquista dos lotes e algumas profissões. Constam entre as ruas do Jardim União da Vitória a rua dos sapateiros, dos agricultores, dos marceneiros, dos professores, entre outras. (CAMPONEZ, 2005). Como veremos adiante, os nomes das escolas também seguiu esta lógica.

As obras executadas no Jardim União da Vitória foram reivindicadas e acompanhadas de perto pelos moradores. Muitos protestos foram organizados quando era necessário pressionar o poder público.

A título de exemplo, consta em uma reportagem da Folha de Londrina que, em fevereiro de 1993, uma comissão de moradores, liderada pelo presidente da Associação de Moradores, na época Sebastião Rodrigues, se dirigiu à prefeitura e foi recebida pelo prefeito. As queixas eram em torno da necessidade de modelar as ruas e do alto índice de desemprego dos moradores do bairro. Após negociações, os manifestantes saíram da prefeitura com a promessa de que as ruas seriam modeladas em breve e que alguns moradores seriam empregados nas frentes de trabalho da prefeitura. (FOLHA DE LONDRINA, 1993).

Em 1995 e 1996, ocorreram vários protestos dos moradores revoltados pela demora da prefeitura em modelar as ruas, o que estava levando os ônibus coletivos a não transitarem no bairro em dias de chuva. Como forma de protesto, no dia 02 de janeiro de 1995, dezenas de moradores do Jardim União da Vitória abriram uma valeta na rua impedindo a passagem do ônibus. $\mathrm{O}$ mesmo protesto ocorreu em agosto do mesmo ano.

Em janeiro de 1996, um grupo de moradores invadiu um ônibus da companhia de transporte coletivo Francovig e obrigou o motorista a desviar a rota original e transitar pelas ruas do bairro. O presidente da Associação de Moradores da época, Pedro da Silva Bonfim, relatou ao repórter do Jornal de Londrina que, após várias tentativas mais amenas, aquela forma radical era a única que restara, a fim de pressionar o poder público a atender as reivindicações antigas dos moradores do Jardim União da Vitória. O entrevero durou horas até que quinze moradores, entre eles uma mulher e várias crianças foram detidos e levados à delegacia. No momento da detenção, houve conflito entre os moradores e a Polícia Militar, que, segundo o Presidente da Associação de Bairros, havia investido com a viatura sobre os moradores. Os moradores detidos foram colocados dentro de dois ônibus da Francovig, que transitaram pelas ruas da cidade, escoltados por cinco viaturas. Segundo a reportagem do Jornal de Londrina, foi um episódio cinematográfico. Após pagar fiança, os moradores detidos foram liberados. (JORNAL DE LONDRINA, 1996).

Esses e muitos outros entreveros ocorreram na formação do Jardim União da Vitória, devidamente registrados nos jornais da cidade. Citamos apenas alguns acima a título de ilustrar a luta popular que permeou a história do bairro. Atualmente, o bairro é dividido em seis partes, União da Vitória I, II, III, IV, V e VI algumas dessas ainda com infraestrutura bem precária, outras já bem organizadas. É o maior bairro da cidade, tendo em média dezesseis mil habitantes. O bairro tem visibilidade no município pela sua capacidade de mobilização popular e de enfrentamentos coletivos para dar 
encaminhamentos aos problemas que surgem no cotidiano. (CAMPONEZ, 2005). Os conflitos citados acima são referendados por Maria da Paz, uma das primeiras moradoras do Jardim União da Vitória.

Quando eu cheguei era em torno de quinze a vinte casinhas aqui no bairro. Hoje a gente tem farmácia, mercado muito bom, lutamos pela água, pela luz, pelo asfalto, pelo posto de saúde, pelas escolas. Hoje o melhor posto de saúde da região é o nosso, atende dezesseis horas. Enfrentamos polícia. Fomos presos na época. Eu não fui porque fui esperta porque corri [risos]. Mas, os meus parceiros de luta foram presos. Me lembro como se fosse agora. Arrumamos um advogado, fomos no Banco. Ele tirou uma quantia, pagamos a fiança e liberamos todo mundo, graças a Deus. E aí o bairro só foi evoluindo. Ainda tem muito problema, mas teve muita evolução sim. (MARIA DA PAZ, 2011).

Dessa forma, fica evidente as conquistas dos bairros pobres das cidades não chega apenas pelas mãos de representantes do poder público, como é alardeado em suas propagandas políticas. As conquistas são fruto de árduo esforço coletivo dos moradores, que, para serem lembrados, precisam se fazer perceber através de inúmeras mobilizações.

As escolas do Jardim União da Vitória também foram sendo conquistadas nesse processo contínuo de luta, de reivindicação e de protestos. Abordaremos a seguir a luta pelas escolas e pelas melhorias nelas.

\section{Luta pelas escolas públicas do bairro}

A reivindicação pela construção de escolas públicas no Jardim União da Vitória também fez parte dos pleitos encaminhados pelos moradores do bairro.

Em novembro de 1995, conforme reportagens dos jornais locais, foi organizada uma comissão de educação que fez uma manifestação na Prefeitura de Londrina. A comissão era liderada por Maria Tereza Rui Santiago, moradora do Jardim União da Vitória. Os moradores chegaram à prefeitura de posse de cartazes reivindicativos, em dois ônibus cedidos pela empresa de transporte coletivo Francovig. A empresa resolveu colaborar, cedendo o transporte, para evitar que os moradores ocupassem o ônibus para ir à Prefeitura, segundo informação dada pelo engenheiro da empresa à repórter da Folha de Londrina. (BARONI, 1995).

Em passeata, cerca de cem manifestantes, entre eles homens, mulheres e crianças, adentraram a Prefeitura para cobrar a construção de uma escola de primeiro grau (hoje fundamental I), que havia sido prometida em 1994, mas, até aquela data, ainda não havia saído do papel. Segundo os moradores, quase mil crianças estavam sem condições de estudo por falta de salas de aulas no bairro.

Em um levantamento feito pelos próprios moradores, cerca de oitocentas e quarenta e três crianças estavam estudando em escolas de outros bairros da região. Entretanto, as famílias não tinham como custear as passagens de ônibus para a locomoção de seus filhos até a escola. (BARONI, 1995).

Havia também a dificuldade de locomoção devida à má estrutura das vias do bairro, que impedia o trajeto dos ônibus em dias de chuva.

A primeira escola do União da Vitória foi a Escola Municipal Barbara Falcovski Vieira $^{6}$, construída no ano de 1993, na gestão municipal de Cheida (PMDB). Entretanto, ela atendia apenas o primeiro grau (Fundamental I) e tinha, na época, setecentos e cinquenta e oito alunos matriculados. 
Maria Tereza Santiago relatou à repórter do Jornal de Londrina que havia um descontentamento em relação ao encaminhamento que o Secretário de Educação, Luís Carlos Brushi, e a Secretária de Ação Social, Márcia Lopes, vinham dando aos pleitos do Jardim União da Vitória. Os dois secretários haviam sido convidados para uma reunião no bairro, mas não haviam comparecido. (QUERINO, 1995).

Conforme o Secretário da Educação, a construção da escola prometida desde 1994 estava sendo obstada, por conta da extinção do Programa Estadual de Desenvolvimento Urbano (PEDU), pelo Governo Estadual de Jaime Lerner (PSDB). No lugar deste programa, foi criado outro, o Paraná Urbano. Essa alteração atrasou a destinação das verbas que estavam programadas no planejamento do PEDU.

O Secretário da Educação informou aos moradores que a construção do Centro de Atendimento Integral à Criança ${ }^{7}$ (CAIC), prevista para fevereiro de 1996, atenuaria a falta de vagas no bairro. O CAIC iria atender os moradores do Jardim União da Vitória e bairros adjacentes - Jardim Franciscato, Jardim Perobal e Jardim Santa Joana.

A menção que o Secretário de Educação fez a respeito do CAIC irritou os manifestantes, conforme a reportagem da Folha de Londrina. (BARONI,1995). Para Maria Tereza, a construção da referida escola não solucionaria o problema de falta de vagas. Segundo ela, o CAIC estava sendo construído para atender vários bairros da região sul, e o número de vagas previsto não atenderia nem ao menos a demanda do Jardim União da Vitória.

A manifestação terminou com um acordo entre o Secretário da Educação e os moradores. Ficou definido que a prefeitura garantiria o transporte das crianças do bairro que estivessem matriculadas em outras escolas da região, enquanto não fosse construída a escola. Houve, também, o compromisso de que o CAIC atenderia aos alunos de $5^{\mathrm{a}}$ a $8^{\mathrm{a}}$ séries, no período noturno. A prefeitura se comprometeu em solicitar a intermediação do governo do Estado para conseguir os professores dessas turmas, haja vista que estas séries eram de competência do governo Estadual e não do governo Municipal. (BARONI, 1995).

Segundo Rosalina, em entrevista, a construção do CAIC estava prevista para acontecer na região norte do Estado do Paraná. O governo ainda não havia decidido em qual município ela ocorreria, porém havia a possibilidade de ser construído em Rolândia PR, cidade próxima a Londrina. De acordo com Rosalina, foi a luta dos moradores dos bairros que conseguiu encaminhar os pleitos ao poder público e conquistar a construção do CAIC, na região sul de Londrina.

A princípio, o CAIC não seria construído no Jardim União da Vitória e sim no bairro vizinho - Jardim Franciscato. Rosalina organizou uma comissão de educação com a finalidade de realizar um levantamento, com os moradores do bairro, que atestasse a demanda de vagas escolares que havia ali. Os dados foram enviados para o secretário da educação. Quando o projeto do CAIC foi liberado, não havia terreno com a área exigida para sua construção. A partir de novas negociações com os moradores, a Prefeitura desapropriou um terreno no jardim Cristal, bairro vizinho ao Jardim União da Vitória, no qual o CAIC foi construído.

Maria da Paz confirma na entrevista que

O CAIC veio pro bairro porque a gente fez frente de luta lá na prefeitura. Conseguimos até escolher quem seria o diretor da escola. O diretor veio, depois quiseram tirar ele. E aí a gente queria que ele ficasse e fizemos um abaixo assinado e levamos até o prefeito e pra nossa vitória o nosso candidato ficou como diretor geral do CAIC. (MARIA DA PAZ, 2011). 
Maria da Paz e Rosalina nos relataram que tiveram como motivo de indicação do diretor o bom trabalho que ele vinha desenvolvendo na escola Municipal Elias Kauam Jardim Novo Amparo -, que chegou ao conhecimento de alguns moradores do União da Vitória. Embora nessa época o cargo de diretores já fosse ocupado por eleição direta, como vimos anteriormente, a prefeitura aceitou essa excepcionalidade devido ao fato de a escola constar com dualidade administrativa.

Os diretores entrevistados reafirmam a luta dos moradores na conquista da escola.

\begin{abstract}
Ah, eles participaram da conquista das escolas sim. Eu por exemplo fui convidado pra ser diretor aqui no CAIC. Quem sugeriu para o Cheida [prefeito da época] o meu nome foram os moradores do bairro. (DIRETOR GERAL DO CAIC, 2011).
\end{abstract}

A comunidade batalhou muito para que a escola viesse pra cá. Eles lutaram sim, tanto que o nome da escola foi dado por eles como Zumbi dos Palmares, porque eles acreditavam que Zumbi era forte guerreiro e lutador assim como eles e assim eles se compararam a Zumbi dos Palmares [...] assim foi escolhido o nome da escola. (DIRETORA DA ESCOLA ZUMBI DOS PALMARES, 2011).

O CAIC da zona sul de Londrina ficou nominado "CAIC Dolly Jess Torresin". Em sua dependência, funcionava a escola municipal de ensino fundamental I, nominada Zumbi dos Palmares, e a escola estadual de ensino fundamental II, nominada Thiago Terra. A escolha dos nomes das escolas também foi feita pelos moradores do bairro, seguindo o que ocorreu com o nome das ruas. Essa instituição iniciou suas atividades em 11 de novembro de 1996. Sua inauguração contou com a presença do então Ministro da Educação do governo Federal, Paulo Renato, outras autoridades de Londrina e também com muitos moradores do Jardim União da Vitória e bairros adjacentes. As atividades começaram no ano letivo seguinte, 1997. (ESCOLA MUNICIPAL ZUMBI DOS PALMARES, 2010).

No CAIC, houve dualidade administrativa até o ano de $2009^{8}$, ou seja, a administração era em parceria entre o Estado e o Município. A administração da escola, até este ano, contava com um diretor geral da unidade e mais duas diretoras distintas: uma para o ensino fundamental I e outra para o ensino fundamental II.

Embora a luta pela instalação do CAIC na zona sul tenha tido êxito, a ampliação de vagas não atendeu à demanda do União da Vitória, conforme havia sido antecipado pelos moradores do bairro. Dessa forma, a luta pela ampliação das vagas continuava.

Em outubro de 2000, novamente houve protesto dos moradores em prol da construção de mais instalação para uma escola da região sul de Londrina. Conforme Rodrigues (2000), mais de trezentos moradores do Jardim União da Vitória, em conjunto com moradores de bairros adjacentes, foram às ruas reivindicar a desocupação de um terreno no Jardim Santa Joana, que havia sido doado à Prefeitura. No terreno, seria construída a Escola Estadual Rina Francovig.

A escola já funcionava desde o ano de 1993, mas dividia o prédio com uma escola municipal da região. Durante o dia, o prédio atendia oitocentos alunos de primeira a quarta série do município. À noite, atendia quatrocentos adolescentes e adultos do curso supletivo, distribuídos da quinta a oitava séries (hoje EJA). O bairro continuava com demanda reprimida de cerca de mil vagas.

Os moradores organizaram um abaixo assinado e levaram ao Prefeito para que apressasse a negociação da desocupação do terreno no qual a escola seria construída. A assessora de planejamento da Secretaria Municipal de Educação, Carmem Lucia Baccaro, 
informou à repórter da Folha de Londrina que a construção da nova escola ampliaria a oferta da região em torno de mil vagas e atenderia uma reivindicação antiga dos moradores, pois ofertaria também o Ensino Médio. (RODRIGUES, 2000). A construção do prédio só foi concretizada no ano de 2002.

A luta dos moradores do Jardim União da Vitória não acaba na conquista das escolas do bairro. Como veremos a seguir, era preciso ainda lutar pelo direito de matricular os filhos nas escolas mais próximas às suas moradias. Era preciso lutar, também, para que as crianças tivessem condições seguras no trajeto de casa para a escola.

\section{A luta dos moradores pelo direito à vaga na escola próxima às moradias}

Em 2005, a falta de vagas nas escolas do bairro ainda fazia os alunos se deslocarem para escolas de regiões próximas ou centrais. Esse problema se repetia em outros bairros periféricos da cidade. Para ir às escolas, as crianças ficavam expostas à superlotação dos transportes coletivos e à falta de segurança que o traslado de suas casas às escolas causava.

Segundo Leão (2005, p. 3), no terminal central de transporte coletivo de Londrina, logo após o término das aulas, várias crianças, algumas bem pequenas, entravam - e continuam entrando - sozinhas nos ônibus e se arriscavam em travessias perigosas na frente deles.

No final de 2006, a falta de vagas no CAIC para o ano de 2007 revoltou os moradores e provocou nova onda de protestos. Alguns pais estavam sendo encaminhadas para matricular seus filhos na Escola Estadual Prof ${ }^{a}$ Vani Ruiz Viesse, no Jardim Franciscato. Essa escola, segundo os manifestantes informaram à repórter da Folha de Londrina, ficava a dez quilômetros ${ }^{9}$ de distância do Jardim União da Vitória. Os moradores se negavam a aceitar essa situação e a matricular seus filhos em escolas distantes de casa. Um trabalhador morador do bairro, o pedreiro Luiz Antônio Patrocínio, assim afirmou,

Eu não vou matricular minha filha, mesmo que seja preso por isso. Aí o governo vai conhecer um trabalhador que foi preso por não querer ameaçar a segurança de uma criança. [...] Eu não tenho como deixar minha filha andar sozinha essa distância. Eu trabalho e não tenho como acompanhá-la até lá. (BORGES, 2006, p.3).

A presidente da Associação de Pais e Mestres da escola, Maria Helena dos Anjos, também estava sendo solicitada a transferir seu filho para a escola Vani Ruiz Viesse. Indignada, argumentou: "É um direito dele estudar? É sim, mas com segurança. Eu não vou matricular meu filho em uma escola onde não sei se ele volta, porque o caminho é perigoso, tem ruas movimentadas. Ele é uma criança!”. (BORGES, 2006, p. 3).

Para a Secretaria Estadual de Educação, não havia falta de vagas na região, pois, segundo o georreferenciamento ${ }^{10}$, as vagas eram suficientes se considerados as vagas das escolas do Jardim União da Vitória e dos bairros adjacentes, que cobriam a demanda daquela região. $\mathrm{O}$ que ocorreu, nesse caso, foi que cerca de cinquenta alunos que estudavam no CAIC na $4^{\mathrm{a}}$ série em 2006, ficaram sem vagas na $5^{\mathrm{a}}$ série em 2007.

As vagas haviam sido preenchidas por alunos indicados pelo georreferenciamento. Não haveria salas para comportar todos os alunos do Jardim União da Vitória, se todas as matrículas fossem aceitas no CAIC.

Os moradores procuraram orientação com a promotora da vara da Infância da cidade de Londrina. Foram orientados por ela a entrar com um mandato de segurança para poderem matricular seus filhos em escola próxima às suas casas. Foi instituída uma 
comissão de moradores, que elaborou um documento e encaminhou para o NRE. A resposta do NRE, pela coordenadora de logística educacional, foi que as crianças haviam sido transferidas do CAIC para outros colégios da região por falta de vagas. Informou que a melhor coisa que os pais poderiam fazer era matricular os filhos na escola mais próxima indicada e deixar os nomes dos filhos no cadastro do CAIC. Ocorria que a escola mais próxima, segundo os moradores, ficava muito distante.

Em janeiro de 2006, segundo a referida coordenadora, as vagas existentes nas escolas da região seriam adequadas para atender os moradores da melhor forma possível. Os moradores se negaram a proceder assim, sob o argumento de que, se agissem conforme a orientação estariam concordando com ela e, dessa forma, perderiam o poder de negociação. (BORGES, 2006, p. 3).

O difícil acesso à escola provocou outras mobilizações e protestos no Jardim União da Vitória.

Em julho de 2008, foram os próprios estudantes, nesse caso um grupo de mais de trinta crianças, com idade por volta de onze anos, que foram atores do protesto. (AUGUSTO, 2008). Ao retornarem da escola para casa, um estudante de onze anos foi atropelado na Avenida Guilherme de Almeida, em frente à escola. A avenida, segundo os moradores do Jardim União da Vitória, era perigosa, mal sinalizada, sem condições de caminhar a pé. Várias manifestações já haviam sido realizadas pelos moradores, a fim de que melhorias fossem realizadas na rua.

Diante do atropelamento do aluno, o grupo de estudantes interrompeu o tráfego na avenida, ateando fogo em madeiras e pneus. A mobilização foi para chamar a atenção para a necessidade de melhorar a sinalização e recuperar a viela para pedestres que margeava a avenida. A condição precária da viela obrigava os estudantes a caminhar, perigosamente, pela avenida.

Enquanto o protesto ocorria, um estudante avisou a mãe da criança que havia sido atropelada. A mãe, Rosilene Moreira, encontrou o filho desacordado no Hospital Infantil. Ela informou ao repórter da Folha de Londrina que tentou colocar o filho em escola mais próxima a sua residência. No entanto, não conseguiu vaga, e não houve outra forma de o filho continuar os estudos senão se arriscando naquele trajeto. (AUGUSTO, 2008).

Como vimos até aqui, aquilo que os moradores identificaram como necessidade não era visto como necessário pelo poder público e sua racionalidade administrativa. Ou seja, os moradores continuavam atestando a falta de vagas e/ou de condições seguras para o acesso à escola mais próxima às residências, mas o governo, representado pelo NRE e suas secretarias, atestava que as vagas existiam.

Assim, o Estado/NRE entendia que, se havia vagas nas escolas das imediações do Jardim União da Vitória, a questão quantitativa/formal estava resolvida. Mas, os moradores viam o movimento das crianças que precisavam se deslocar do Jardim União da Vitória para outras regiões. O bairro ainda hoje tem algumas ruas sem iluminação, sem asfalto, sem segurança para chegar ao bairro mais próximo, onde estava localizado o colégio com vagas para matrículas. Nesse contexto, muitas famílias desestimularam seus filhos a se matricularem nas escolas dos bairros vizinhos, pois consideraram perigoso o trajeto. Isso explica o alto nível de evasão escolar, não só no bairro analisado nesse estudo, mas em grande parte das regiões pobres do país.

A mobilização dos moradores do Jardim União da Vitória não se restringiu apenas à conquista de vagas nas escolas. Como veremos a seguir, conforme as vagas foram sendo conquistadas, concomitantemente, novas demandas e problemas apareciam e solicitavam outras mobilizações e ações. 


\section{Luta pela manutenção da escola}

O CAIC Dolly Jess Torresin, como vimos, iniciou suas atividades em 1997. A proposta era que as crianças do Ensino Fundamental I (na época $1^{\mathrm{a}}$ a $4^{\mathrm{a}}$, hoje $1^{\mathrm{a}}$ a $5^{\mathrm{a}}$ séries) tivessem atendimento em turno integral. Portanto, precisavam fazer as refeições na escola. No entanto, constantemente, os alunos eram dispensados por falta de merenda escolar. Esse fato levou a mais uma manifestação dos moradores do Jardim União da Vitória, no dia 22 de maio de 1997, na Prefeitura de Londrina.

Conforme Mendonça (1997), três fatores levaram à mobilização dos moradores: a falta de merenda, a falta de professores e funcionários e a falta de segurança na escola. Mais de cem moradores do Jardim União da Vitória e de outros bairros atendidos pelo CAIC entraram na Prefeitura no dia 22 de maio de 1997, erguendo cartazes e gritando palavras de ordem, exigindo melhorias para o CAIC.

O protesto foi organizado pela Associação de Pais e Mestres do CAIC, que contou com o apoio da Associação de Moradores e outras entidades da região. A Associação de Pais e Mestres tinha como presidente, na época, Nelson Cardoso ${ }^{11}$.

Como o Prefeito Antonio Belinati estava viajando, o grupo foi atendido pelo Secretário de Negócios Jurídicos, Eduardo Duarte Ferreira. Os moradores se queixavam de que as crianças estavam retornando para as casas pela falta de merenda e de professores. Ocorria ainda que os alunos estavam auxiliando no feitio da merenda e na limpeza da escola devido à falta de contratação de funcionários. Muitos alunos que voltavam para casa não tinham como retornar à escola, pois residiam longe dela.

O protesto terminou com a apresentação de algumas soluções pelo secretário, que informou aos moradores que a Prefeitura iria remanejar funcionários de outras escolas para atender o CAIC e que a Polícia Militar seria solicitada a auxiliar na questão da segurança. Houve, ainda, o compromisso de que haveria a aquisição de merenda que fosse suficiente para abastecer o CAIC.

O presidente da APM, Nelson Cardoso, informou à repórter do Jornal de Londrina, que aquelas medidas não resolveriam os problemas apresentados. Remanejar funcionários entre as escolas de nada adiantaria, pois não havia funcionários sobrando nas outras escolas. O remanejamento já tinha sido prometido e, até a data da manifestação, ainda não havia acontecido. Segundo ele, a Polícia Militar também não tinha força de trabalho para cumprir a promessa de melhorar a segurança nas escolas. O diretor da escola declarou à reportagem do jornal que os próprios moradores estavam se revezando para cuidar da segurança da escola e fazendo outros serviços para mantê-la funcionando. Grande parte dos problemas daquela escola estava relacionada à dualidade administrativa prevista, idealmente, pelo Programa Nacional de Atenção Integral à Criança e ao adolescente ( PRONAICA). Na prática, os governos estadual e municipal não conseguiram desenvolver a integração necessária para o bom desenvolvimento dos CAICs e muito deles soçobraram. No município de Londrina, os dois CAICs que foram construídos nas zonas sul e norte, atualmente foram municipalizados.

$\mathrm{Na}$ entrevista, o ex-diretor geral do CAIC afirmou que, desde seu início, o CAIC Dolly Jess Torresin funcionou com muita dificuldade. $\mathrm{O}$ fato de a escola funcionar em parceria com recursos do município e do estado causava muita confusão e ingerência e, na prática, era quase que inviável. Era muito difícil pensar em dois projetos de escola (municipal e estadual), sendo que a escola era uma só. Por exemplo, a Prefeitura previa orçamento para as oficinas que atendia alguns alunos no turno contrário àquele que estudavam. A escola queria estender o recurso aos alunos do Ensino fundamental II (do 
Estado), mas não podia, porque o recurso era da prefeitura, que não admitia financiar atividades para alunos que deveriam ser custeados pelo estado.

A saída que a escola achou foi ofertar as oficinas aos alunos do estado (Fundamental II) em sistema de parceria com outras instituições. Dessa forma, as oficinas passaram a acontecer em parceria com o Serviço Social da Indústria (SESI), com a Universidade Estadual de Londrina (UEL) e outras instituições públicas, privadas e filantrópicas. Havia oficinas de mecânica automotiva, de padaria, viveiro de plantas e outras. Os profissionais que trabalhavam nestas oficinas eram pagos com os recursos conseguidos via APMF. As atas do conselho escolar e da APMF analisadas por nós, também reafirmam esta questão.

$\mathrm{O}$ ex-diretor conta que houve ainda a possibilidade de estabelecer parceria com um agrônomo e com um assentamento em Rolândia, para produzir e comercializar mudas de palmeira real. Nas oficinas os alunos produziam e ensacavam as mudas, que eram entregues no assentamento. Produziram também Amarílis Vermelhas com os alunos da oitava série e com o grêmio estudantil. Com os recursos recebidos, a escola comprou uma estufa de plantas.

A oficina de padaria, segundo ele, também deu muito certo. Ela acontecia em parceria com a empresa de ônibus Francovig. Com a comercialização dos pães com esta empresa, houve a possibilidade de a escola adquirir um forno maior para aumentar a produção. Havia, também, as oficinas de esporte, de artes, de música.

Dessa forma, mesmo sem ter a intenção declarada, a instituição desenvolvia atividades de trabalho produtivo no interior da escola, muito próximas àquelas efetivadas pelos pedagogos russos Makarenko (1983) e Pistrak (2000), salvo as especificidades históricas e os modos de produção. Contudo, não tivemos a possibilidade de verificar se havia, de fato, a integração entre trabalho, ensino e cultura ou se estas atividades ocorriam de forma estanque e não integrada, o que é mais provável.

Atualmente, como já afirmamos, o CAIC foi municipalizado. Sua denominação a partir de 2009 passou a ser apenas Escola Municipal Zumbi dos Palmares, conforme a diretora atual nos explicou. As oficinas continuam a acontecer, mas agora com recursos da prefeitura e atendendo apenas trinta e cinco por cento dos alunos da escola.

\section{Conclusão}

Nosso ponto de partida, neste texto, foi a premissa de que as lutas populares na área da educação foram importantes para a democratização do ensino público e gratuito, principalmente, em relação ao ensino fundamental. Tendo em vista apontar elementos e fatos que sustentassem e afirmassem nossa ideia central, apresentamos no texto as dinâmicas recorrentes na trajetória das lutas pela educação, abordando o ponto de vista dos trabalhadores pobres dos bairros periféricos das cidades, em específico, daqueles que residiam no Jardim União da Vitória em Londrina-PR.

A título de conclusão, esperamos ter conseguido demonstrar que a ampliação do sistema público de ensino na região pesquisada foi produto de uma luta árdua, lenta e cotidiana dos moradores dos bairros, que conseguiram se organizar, diante das condições desiguais a que estavam e continuam submetidos. Essas lutas se traduziram na conquista das escolas, no acréscimo das vagas nos níveis e modalidades da educação e, ainda, na conquista das condições mínimas para permanecer na escola conquistada. Desta forma, reiteramos que a luta popular na área da educação foi e continua sendo condição sine qua 
non para a democratização do sistema público de ensino nos bairros periféricos e pobres das cidades.

\section{Referências}

AUGUSTO, Luciano. Crianças partem para a briga... por direitos: fatos recentes mostram que elas estão agindo por conta própria para atrair a atenção para problemas da comunidade. Folha de Londrina, Londrina, 13 jun. 2008. Caderno Cidades, p. 1.

AVANCINE, Sérgio. Daqui ninguém nos tira: mães na gestão colegiada da escola pública. 1990. Dissertação (Mestrado em Educação) - Pontifícia Universidade Católica de São Paulo, São Paulo.

BARONI, Célia. Bairro Cobra a Construção de Escola. Folha de Londrina, Londrina, 30 nov. 1995. Primeiro Caderno, p. 5.

BORGES, Guilherme. Pais protestam contra mudança de escola. Moradores do União da Vitória querem que filhos continuem no CAIC e alegam que outra instituição fica a $10 \mathrm{~km}$ de distância. Folha de Londrina, Londrina, 14 dez. 2006. Caderno Cidades, p. 3.

CAMPONEZ, Adriana Andrela. A Politização do Urbano: a experiência dos moradores do Jardim União da Vitória na conquista dos direitos de cidadania e da cidade. 2005. $132 \mathrm{f}$. Dissertação (Mestrado em Ciências Sociais) - Universidade Estadual de Londrina.

CAMPOS, Maria Machado Malta. Escola e participação popular: a luta por educação em dois bairros de São Paulo. 1982. 608 f. Tese (Doutorado em Ciências Sociais) - Faculdade de Filosofia, Letras e Ciências Humanas. USP, São Paulo.

CAMPOS, Rogério Cunha. A luta dos trabalhadores pela escola. São Paulo: Loyola, 1989.

CASTELLS, Manuel. Cidade, democracia e socialismo: a experiência das associações de vizinho de Madri. Rio de Janeiro: Paz e Terra, 1980.

CUNHA,Luiz Antônio. Educação, Estado e Sociedade no Brasil. 2 ed. São Paulo: Cortez, 1995.

ESCOLA MUNICIPAL ZUMBI DOS PALAMARES. Projeto Político-Pedagógico. Londrina, 2010.

FOLHA DE LONDRINA. Moradores ameaçam fechar rodovias. Londrina, 14 fev. 1993, p. $12 b$.

GHANEM JR., Elie George Guimarães. Lutas populares, gestão e qualidade da escola pública. 1992. Dissertação (Mestrado em Educação) - Faculdade de Educação, Universidade de São Paulo, São Paulo.

GOHN, Maria da Glória. Movimentos Sociais e Educação. 2 ed. São Paulo: Cortez, 1994.

INSTITUTO BRASILEIRO DE GEOGRAFIA E ESTATÍSTICA. Censo, 2010.

Resultados gerais da amostra. Cidades do Paraná. Brasília, 2010. Disponível em:

<http://www.ibge.gov.br/cidadesat/topwindow.htm?1>. Acesso em: 14 ago. 2011.

JORNAL DE LONDRINA. Moradores desviam ônibus para o bairro. Londrina, 13 jan 1996, p. 6. 
LEÃO, Silvana. O difícil trajeto da escola para casa: crianças que dependem de transporte coletivo para estudar ficam expostas à superlotação e falta de segurança. Folha de Londrina, Londrina, 18 de mar. 2005. Caderno Cidades, p. 3.

MAKARENKO, Anton Semionovich. Poema Pedagógico. São Paulo: Brasiliense, 1983.

MENDONÇA, Gisele. Zona Sul pede melhorias no CAIC. Jornal de Londrina, Londrina, 22 mai. 1997. p. 6.

NÚCLEO REGIONAL DE EDUCAÇÃO (Londrina). Site oficial. Disponível em: $<$ http://www.gestaoescolar.diaadia.pr.gov.br/modules/conteudo/conteudo.php?conteudo=2 $>$. Acesso em: 05 maio 2010.

NUNES, Edison; JACOBI, Pedro. Movimentos Populares Urbanos e a Conquista da Democracia. In: MOISÉS, José A. et al. Cidade, povo e poder. Rio de Janeiro: Paz e Terra, 1982. p. 165-199.

PISTRAK, Moisey Mikhaylovich. Fundamentos da Escola do Trabalho. São Paulo: Expressão Popular, 2000.

QUERINO, Régis. União da Vitória quer Escola. Jornal de Londrina, Londrina, 30 nov. 1995.

RODRIGUES, Betânia. Moradores exigem lote para escola. Folha de Londrina, Londrina, 26 out. 2000. Caderno Cidades, p. 3.

SILVA, Willian Ribeiro da; MELCHIOR, Lirian. Estruturação urbana sob o contexto da mobilidade populacional em Londrina, Brasil. Revista Bibliográfica de Geografía y Ciencias Sociales. Barcelona, v.8, n. 341, 10 jan. 2002. Disponível em: http://www.ub.es/geocrit/b3w-341.htm. Acesso em: 28 abr. 2011.

SOBRINHO, José Amaral; PARENTE, Marta Maria de Alencar. CAIC: Solução ou Problema? IPEA. Instituto de Pesquisa Econômico Aplicada. Brasília, jan. 1995.

Disponível em: <http://www.ipea.gov.br/pub/td/td_363.pdf> Acesso em: 10 maio 2012.

SPÓSITO, Marília Pontes. A ilusão Fecunda: a luta por educação nos movimentos populares. São Paulo: EDUSP, 1993.

SPÓSITO, Marília Pontes. O povo vai à escola: a luta popular pela expansão do ensino público em São Paulo. São Paulo: Loyola, 1984.

ZINN, Howard. La outra historia de los Estados Unidos (Desde 1482 hasta hoy). Hondarribia: Lizarra, 2005.

Notas

\footnotetext{
${ }^{1}$ Doutora em Educação pela Universidade Estadual “Julio de Mesquita Filho” - UNESP/Marília. Docente do curso de Pedagogia na Universidade Estadual de Londrina - Departamento de Educação.

${ }^{2}$ Analisamos apenas as atas da Escola Municipal Zumbi dos Palmares e do Colégio Estadual Thiago Terra. Não tivemos acesso às atas das demais escolas.

${ }^{3}$ Estamos nos referindo por democratização à garantia de acesso e permanência na escola.

${ }^{4}$ A autora faz um estudo bastante detalhado sobre a politização do Jardim União da Vitória a partir de reportagens de jornais locais. Nosso objetivo, neste item, porém, é apenas apontar dados relevantes sobre a história do bairro para situar nosso objeto: a luta popular pela escola nesta região. A leitura do estudo de
} 
Camponez foi importante, pois, a partir dela, vislumbramos a possibilidade de colher dados nos jornais que são veiculados em Londrina.

${ }^{5}$ Camponez (2005) cita várias reportagens veiculadas pelo jornal da cidade.

${ }^{6}$ Atualmente, esta escola não existe mais. Ela foi integrada com a Escola Municipal Zumbi dos Palmares, por motivos explicados com mais dados na sequência - municipalização do CAIC.

${ }^{7}$ O CAIC é parte do PRONAICA: Programa Nacional de Atenção Integral à Criança e ao adolescente criado pelo Governo Federal em 1993, no governo Collor. Prevê "ações de atenção integral à criança e ao adolescente, de forma descentralizada, articulada e integrada, por meio do [financiamento] dos órgãos federais, estaduais e municipais e organizações não-governamentais". (SOBRINHO; PARENTE, 1995, p. 8). Essa organização gerou fragmentação de ações e criou dificuldades para a efetivação do programa. O governo Federal se responsabilizou pela construção dos prédios do CAIC em vários municípios. Os governos Estaduais e Municipais deveriam se responsabilizar pela organização e manutenção destes centros, de forma integrada. Como veremos, a proposta de integração foi muito difícil de ocorrer, sendo que muitos CAICs construídos não conseguiram desenvolver a proposta inicial do PRONAICA.

${ }^{8}$ Em 2009, houve um acordo entre o governo estadual do Paraná e o governo municipal de Londrina, que permutaram os prédios das escolas. O colégio estadual do ensino fundamental II, Thiago Terra, passou a funcionar em um prédio próprio, no qual funcionava a escola Municipal Barbara Falcovski. A escola municipal Barbara Falcovski passou a funcionar no CAIC Dolly Jess Torresin, junto com a Escola Municipal Zumbi dos Palmares. Assim, acabou a dualidade administrativa, ficando o CAIC sob a administração apenas da Prefeitura.

${ }^{9} \mathrm{Na}$ verdade, a distância entre o CAIC e a Escola Estadual Vani Ruiz Viesse é de 2,6 km.

${ }^{10}$ Técnica que consiste em fazer um "mapeamento de escolas e residências [...] através da conta de energia elétrica, onde os postes de luz são georreferenciados". (NÚCLEO REGIONAL DE EDUCAÇÃO, 2010, p. 1). Por meio desta técnica, o NRE "distribui e remaneja os alunos conforme a disponibilidade de vagas. No ato da matrícula, o estabelecimento de ensino deve registrar o código de identificação da Copel no cadastro do estudante no sistema do SERE [...]. Com o Georreferenciamento é possível identificar alunos e escolas, localizar residências e vagas escolares e relacionar moradias e critérios de proximidade para garantir as vagas". (idem, 2010, p. 1).

${ }^{11}$ Nelson Cardoso esteve presente na primeira ocupação dos terrenos do Jardim União da Vitória e, anos mais tarde, foi Vereador do Município pelo PT, na 13a Legislatura de 01/01/2001 a 31/12/2004.

Recebido em

março-13

Aprovado em outubro-13 